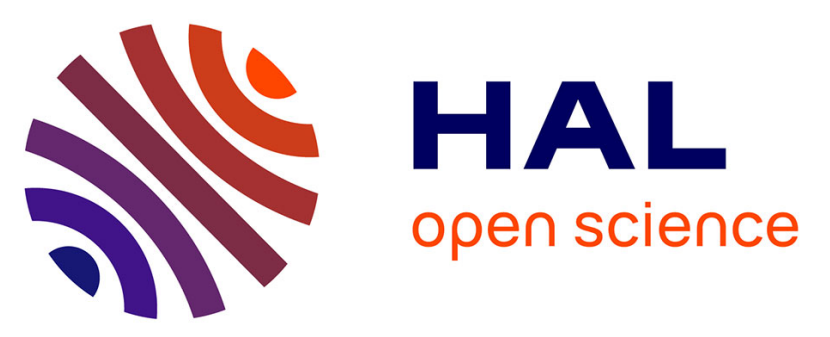

\title{
Simulation of a large power Brushless Synchronous Generator (BLSG) with a rotating rectifier by a reluctance network for fault analysis and diagnosis
}

H K Bui, N Bracikowski, Michel Hecquet, K L Zappellini, J.-P. Ducreux

\section{To cite this version:}

H K Bui, N Bracikowski, Michel Hecquet, K L Zappellini, J.-P. Ducreux. Simulation of a large power Brushless Synchronous Generator (BLSG) with a rotating rectifier by a reluctance network for fault analysis and diagnosis. IEEE Transactions on Industry Applications, 2017, 53 (5), pp.4327-4337. 10.1109/TIA.2017.2701789 . hal-01711113

\author{
HAL Id: hal-01711113 \\ https://hal.science/hal-01711113
}

Submitted on 16 Feb 2018

HAL is a multi-disciplinary open access archive for the deposit and dissemination of scientific research documents, whether they are published or not. The documents may come from teaching and research institutions in France or abroad, or from public or private research centers.
L'archive ouverte pluridisciplinaire HAL, est destinée au dépôt et à la diffusion de documents scientifiques de niveau recherche, publiés ou non, émanant des établissements d'enseignement et de recherche français ou étrangers, des laboratoires publics ou privés. 


\section{Simulation of a large power Brushless Synchronous Generator (BLSG) with a rotating rectifier by a reluctance network for fault analysis and diagnosis}

\author{
H. K. Bui, \\ Univ Lille, Centrale \\ Lille, L2EP, \\ F-59000 Lille \\ France \\ bui.h.kien \\ @ gmail.com
}

\author{
N. Bracikowski \\ IREENA \\ University of Nantes \\ Saint Nazaire \\ France \\ nicolas.bracikowski \\ @univ-nantes.fr
}

\author{
M. Hecquet \\ Univ Lille, Centrale \\ Lille, L2EP, \\ F-59000 Lille \\ France \\ michel.hecquet \\ @ec-lille.fr
}

\author{
K. L. Zappellini \\ EDF R\&D \\ Paris-Saclay \\ France
}

kim-lan.zappellini

@edf.fr

\author{
J. P. Ducreux \\ EDF R\&D \\ Paris-Saclay \\ France
}

jean-pierre.ducreux @edf.fr

\begin{abstract}
The aim of this paper is to simulate a large power brushless synchronous generator (BLSG) used for large turboalternator brushless excitation systems, under conditions of saturation and rotating rectifier diode failures. A reluctance network coupled with electric circuits and power electronic components integrating the movement and nonlinearities of materials has been developed. The approach achieves good compromise between accuracy and computing time for the complete analysis of a 39 phase machine with 117 teeth and 22 poles, and 78 diodes in the associated rectifier bridge. Our model is validated by comparison with experimental measurements and numerical simulation by a finite element package. For the simulations presented, a gain in computation time of 800 can be obtained compared with a finite element model. Different results are calculated for healthy and faulty states to study the impact of open diode block failure. Simulation results show that open diode failures have little effect on the rectified output voltage but the current through diodes and protection fuses increases. The currents in armature phase coil are very affected due to failures. A flux sensor coil can be placed on the stator pole to capture the impact of failures. The harmonic content of the pole flux can be used to monitor and detect diode failures.
\end{abstract}

Index Terms-- Reluctance network, rotating rectifier, diodes, saturation, fault analysis, fault detection.

\section{INTRODUCTION}

Brushless synchronous generators (BLSG) with integrated rotating diode bridges are used to supply the AC turboalternators of nuclear power plants (Fig. 1). They are multiphase salient pole synchronous machines with external rotors and fixed interior inductors (so-called polyphase brushless exciter). The armature winding is placed on the rotor. The rectifier diode bridge mounted on the rotating shaft is fed directly to the field winding of the turbo-alternator without any sliding contacts.

It is necessary to develop a time domain analysis model to predict and understand the constraints on the diodes and the behavior of the generator in transient operating phases (starting, over-excitation, etc.) and in failure mode when a fault occurs in one or more rectifier blocks.

The development of a time domain analysis model must take into account several difficulties. Indeed, the nonlinear behavior of the magnetic part must be taken into consideration, as over-current can occur in various modes.
Moreover, it is not possible to reduce the geometry of the domain studied due to the lack of symmetry.

An attempt to tackle this problem was presented in [1]-[2]. In this model, the magnetic parts are represented as self and mutual inductances in the electrical circuit. These parameters can be calculated numerically using the energy perturbation method [3]. The authors also showed the importance of taking into account the mutual linkage flux of the armature winding end turn, especially in transient fault regime. The effect of magnetic saturation is taken into consideration by introducing a global saturation coefficient that neglects the local behavior of the magnetic circuit. The magnetic behavior of the generator cannot be obtained.

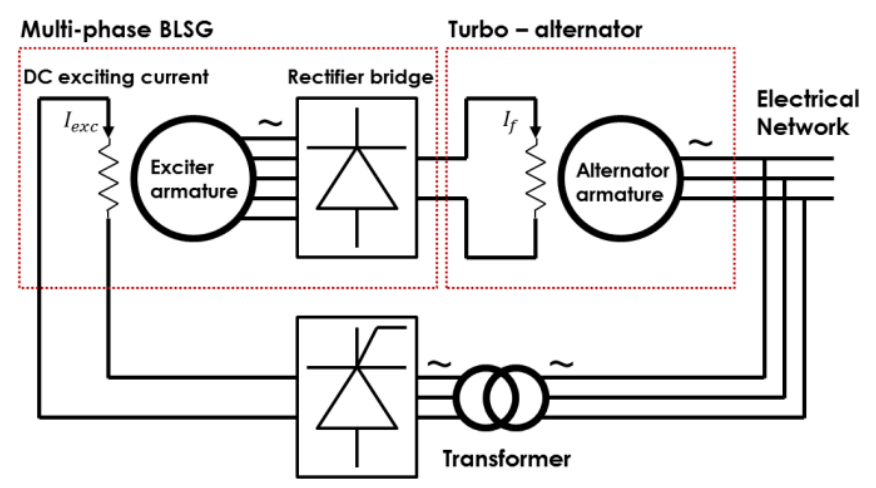

Fig. 1. Schematic diagram of the excitation circuit of the turbo-alternator.

More recently, certain articles have described models for fault detection, such as [4]-[5] for BLSGs with a diode bridge. They are generally based on the "RL" model. The author of [5] proposed to take into account short-circuits between turns that are difficult to simulate. However, as in previous works, several important assumptions are imposed under which the effects of magnetic saturation, rotor saliency, coil span and slot harmonics are neglected.

Nonlinear transient models using 2D finite elements coupled with an external armature electrical circuit can also be used to simulate certain short-circuit fault scenarios [6][7]. These models give good accuracy but require considerable computation time, as reported in [6]. A complete study of multiple fault scenarios for bridge-rectified generators with a large number of phases and diodes is very 
difficult to carry out using finite element models.

Our approach is based on a Reluctance Network (RN) model to perform a full fault analysis that includes the nonlinear magnetic behavior of the machine and the electrical stresses on the rectifier diodes. This approach has been used in many papers and provides a good compromise between computing time and accuracy. As in [8], the authors propose a nonlinear reluctance network model that can be used advantageously for geometry optimization for diagnosing the demagnetization of the surface permanent magnet motor. Robust models based on the permeance network method (PNM) can also be developed to diagnose stator faults [9]. This type of model allows taking into account the local magnetic saturation of the magnetic circuit due to strong stator fault currents and requires shorter computation time compared with finite element method.

The following paragraphs describe the details of our approach and the validation with experimental measurements and numerical simulations using a finite element package. Different results are placed in [10] and different simulations are performed for healthy and faulty states to study the impact of diode block failure.

\section{DESCRIPTION OF THE BLSG}

As shown in Fig. 2, the salient inductor consists of 22 poles each having two flat coils. The rotating armature is mainly comprised of a magnetic circuit, a corrugated type winding and a diode rectifier bridge. It consists of 39 phases connected in polygon configuration. Each phase is connected to two rectifier diodes. The circuit has a total of $2 \times 39$ diodes. The rotational speed of the exciter generator is imposed by the alternator rotor speed, which is generally fixed.

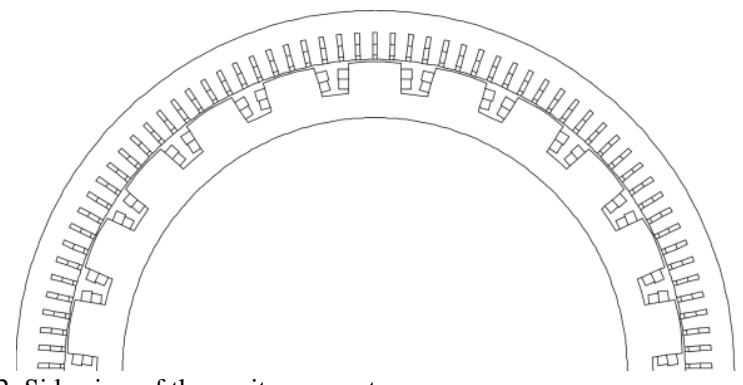

Fig. 2. Side view of the exciter generator

Fig. 3 shows the machine from the electrical point of view where $B_{i}$ denotes the coils. The main data of the exciter are given in Table. I.

TABLE I

MAIN DATA OF THE EXCITER

\begin{tabular}{lll}
\hline Rated power of the turbo-alternator & 1300 & $\mathrm{MW}$ \\
Rated rectified power & 3625 & $\mathrm{~kW}$ \\
Rated rectified voltage & 531 & $\mathrm{~V}$ \\
Rated rectified current & 6823 & $\mathrm{~A}$ \\
Rated RMS phase current & 697 & $\mathrm{~A}$ \\
Rated DC excitation current & 200 & $\mathrm{~A}$ \\
Electrical frequency $\left(f_{e}\right)$ & 275 & $\mathrm{~Hz}$ \\
Speed & 1500 & $\mathrm{RPM}$ \\
\hline
\end{tabular}

\section{RELUCTANCE NETWORK MODELING AND ELECTRICAL CIRCUIT}

In this section, the construction of the Reluctance Network $(\mathrm{RN})$ of the magnetic part of the machine is shown first. Each part of the magnetic circuit is symbolized by its reluctance [11].

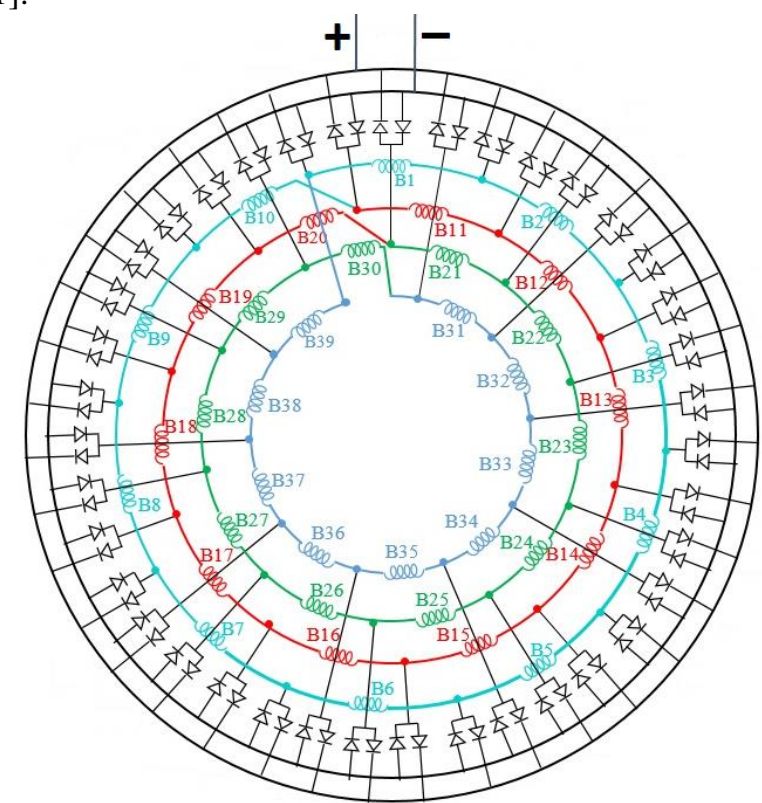

Fig. 3. Electrical diagram of the machine with the rectifier bridge.

The network topology is chosen according to geometrical considerations based on knowledge of the general direction of the flux tubes [12]. The consideration of the magnetic nonlinearity and the rotation is introduced [13]-[14]. Next, the coupling between the magnetic and electrical parts is presented, taking the particularity of the winding into account.

\section{A. Reluctance network}

The composition of the reluctance network is sketched in Fig. 4, where a portion of the inductor with two poles is shown below that of the armature. The circuit of the inductor comprises the nonlinear reluctances of the magnetic part (yoke and pole) and the linear reluctances of the slots between the poles to include leakage flux. The magnetomotive force (m.m.f) sources are corresponding ampere turns of the DC excitation coils. Their distribution in the circuit satisfies Ampere's law for every loop in the RN, for example:

- For loop $1, F_{2}=2 N_{1} I_{1}$

- For loop 2, $F_{1}+F_{2}-F_{2}=2 N_{2} I_{2}$

- For loop $3, F_{1}+F_{2}=2 N_{1} I_{1}+2 N_{2} I_{2}$

Similarly, the circuit of the armature comprises its yoke, teeth and leakage reluctances. The sources introduced are the m.m.f of the AC armature electric current induced in the magnetic circuit. Current directions which depend on the winding configuration must be taken into consideration correctly. The reluctances, i.e. poles/teeth, model the circulation of the magnetic flux in the air-gap between the inductor and the 
armature. To perform simulations with rotation, we use the air-gap reluctance configuration described in [13]-[14]. In this configuration, each pole is connected to every tooth via variable pole/tooth reluctances whose variation is described by the same periodical function but phase-shifted in time.

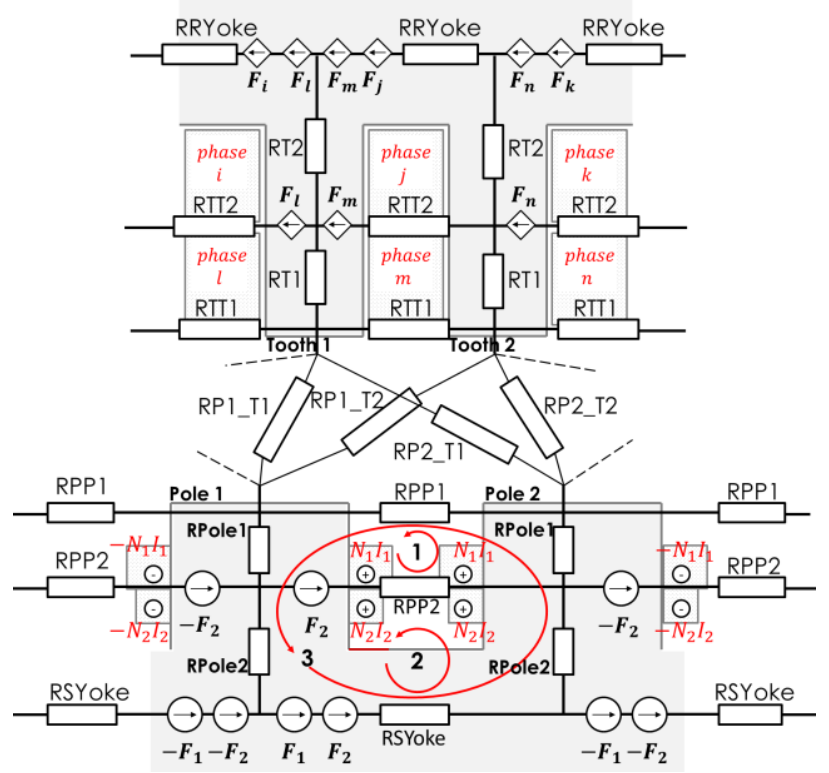

Fig. 4. A portion of the RN showing principal elements.

\section{B. Magnetic nonlinearity}

In our case, the following formula proposed by Marrocco is that best suited for our $\mathrm{B}(\mathrm{H})$ data [15]:

$H=\frac{1}{\mu_{0}}\left(a_{1}+\left(a_{2}-a_{1}\right) \frac{|B|^{2 a_{3}}}{|B|^{2 a_{3}}+a_{4}}\right) B$

Using an optimization-based parameter identification approach, the coefficients $a_{i}$ are determined to fit the provider datasheet. The m.m.f $(\phi)$ relationship equivalent to this formula is written as follows:

m.m.f $=\frac{1}{\mu_{0}} L\left(a_{1}+\left(a_{2}-a_{1}\right) \frac{\left|\frac{\phi}{S}\right|^{2 a_{3}}}{\left|\frac{\phi}{S}\right|^{2 a_{3}}+a_{4}}\right) \frac{\phi}{S}$

where $\phi$ is the magnetic flux through a branch of the magnetic circuit, m.m. $f$ is the value of the current dependent voltage source that models the nonlinear reluctance, and $\mathrm{L}$ and $\mathrm{S}$ are the average length and section of the branch, respectively.

\section{Rotation}

The calculation of the reluctances in the air-gap is described in the following. Our approach is based on the Tooth Contour Method (TCM) presented in [16]-[17] which consists in solving an electrostatic problem in a restricted air- gap region of the machine with appropriate boundary conditions to define the equivalent capacities. The value of the latter is the inverse of the reluctance in a corresponding magneto-static problem. In the TCM, iron regions are not introduced in the computation domain. Only the air gap area, bounded by the contours of the poles and teeth, is considered (Fig. 5). The relative permittivity $\varepsilon_{\mathrm{r}}$ is homogeneous throughout the area and equal to the ratio $\mu_{0} / \varepsilon_{0}=4 \pi 10^{-7} / 8.85$ $10^{-12}$. In this domain, we solve an electrostatic problem defined by the following boundary conditions ( $c f$. Fig. 6):

- We impose a unitary potential on the contour of a pole. This pole is called "activated".

- We apply the boundary condition on the contours of the yoke of the inductor to ensure that the field lines are parallel with these contours.

- A zero potential is imposed corresponds to the other boundaries.

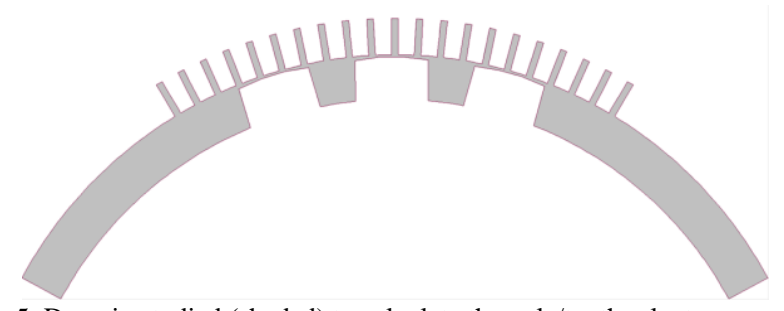

Fig. 5. Domain studied (shaded) to calculate the pole/tooth reluctance.

Fig. 7 shows the distribution of electric induction $\vec{D}$ in the TCM, which is then compared with magnetic induction $\vec{B}$ in a magneto-static simulation. As can be seen, with the boundary conditions chosen, these results show good agreement between the fields. The electrical flux through a selected tooth is then calculated. We then deduce the reluctance value. This calculation is performed for various rotor positions. We finally obtain an evolution of the reluctance between a pole and a tooth as a function of the rotor position.

The curve with red circles in Fig. 8 plots the variation of the reluctance pole/tooth as a function of the position $\theta$ obtained by the TCM method. The angle $\theta$ is the relative position between a pole and a tooth which translates the rotational movement.

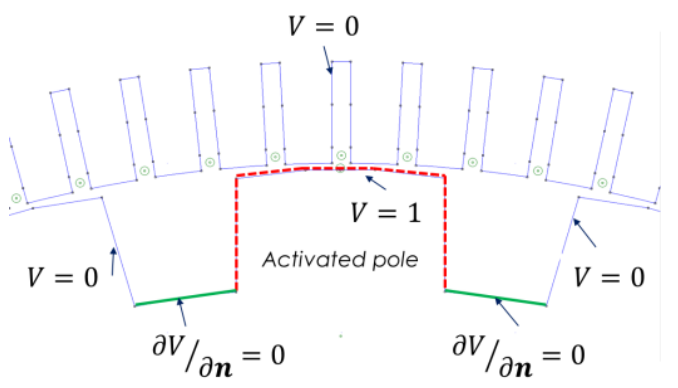

Fig. 6. Application of the boundary conditions.

In this figure, position $\theta=0$ corresponds to pole-tooth alignment. As $\theta$ increases, the tooth moves away from the pole. This variation as a function of $\theta$ can be approximated by a function as follows [18]: 
$R_{\text {Pole/Tooth }}=R_{\max }-\frac{\left(R_{\max }-R_{\min }\right)}{1+\left|\frac{\theta}{\gamma}\right|^{2 \beta}}$

where $R_{\min }$ is the value at $\theta=0, R_{\max }=1000 R_{\min }$ for a sufficiently large value. After a parameter estimation step, it is possible to obtain $\gamma$ and $\beta$. From this function, we can deduce the evolution of the reluctance pole/tooth through time using the relationship $\theta=\Omega t$ where $\Omega$ is the rotating speed.
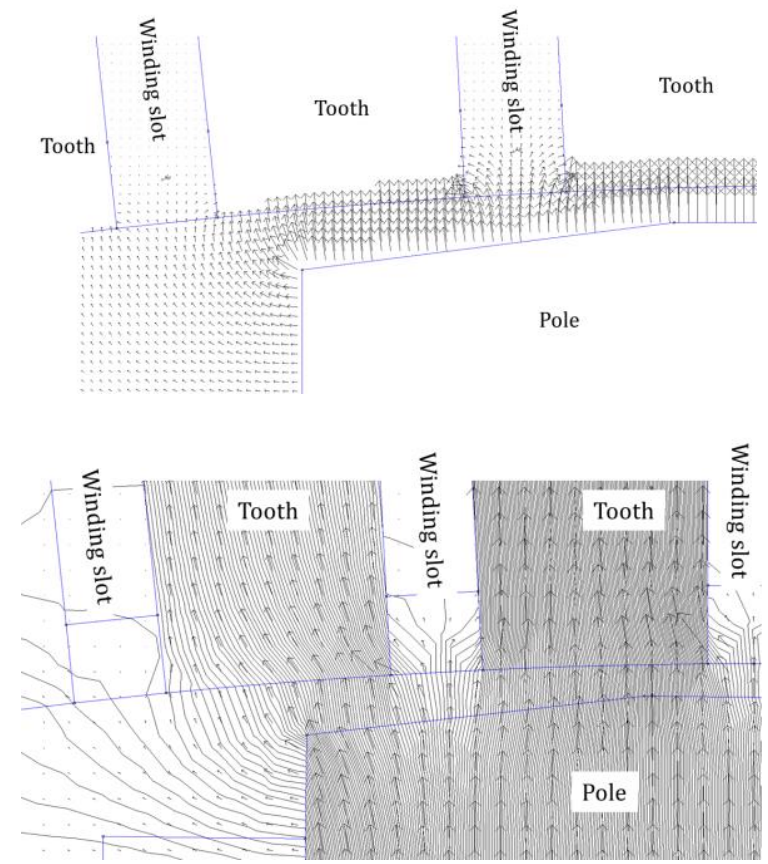

b.

Fig. 7. Distribution of electric induction $\vec{D}$ (a) and magnetic induction $\vec{B}$ (b).

It should be noted that the reluctances vary periodically. The period corresponds to one rotational turn of the machine as the tooth aligns with the pole. In addition, associated with a given pole, the pole/tooth reluctance functions have the same form for all the teeth but are phase-shifted in time. The phase shifts are calculated from the mechanical angle $\Delta \varphi(\mathrm{rad})$ between the teeth.

In order to take into account the variation period and the phase shift between the teeth, we use the following form for the air gap reluctance functions [18]:

$$
\begin{aligned}
& R_{\text {Pole/Tooth }}=R_{\max }-\frac{\left(R_{\max }-R_{\min }\right)}{1+\left|\frac{\Omega t-\Delta \varphi}{\gamma}\right|^{2 \beta}} \mathrm{K} \\
& -\sum_{i=1}^{k}\left(\frac{\left(R_{\max }-R_{\min }\right)}{1+\left|\frac{\Omega t-\Delta \varphi-\left.2 i \pi\right|^{2 \beta}}{\gamma}\right|^{2}}+\frac{\left(R_{\max }-R_{\min }\right)}{1+\left|\frac{\Omega t-\Delta \varphi+2 i \pi}{\gamma}\right|^{2 \beta}}\right)
\end{aligned}
$$

where $\mathrm{k}$ is the desired number of rotational turns in the simulation. The time variation of the reluctance pole/tooth for two adjacent teeth 1 and 2 is plotted in Fig. 9. The latter completes the reluctance network of the machine in static regime.

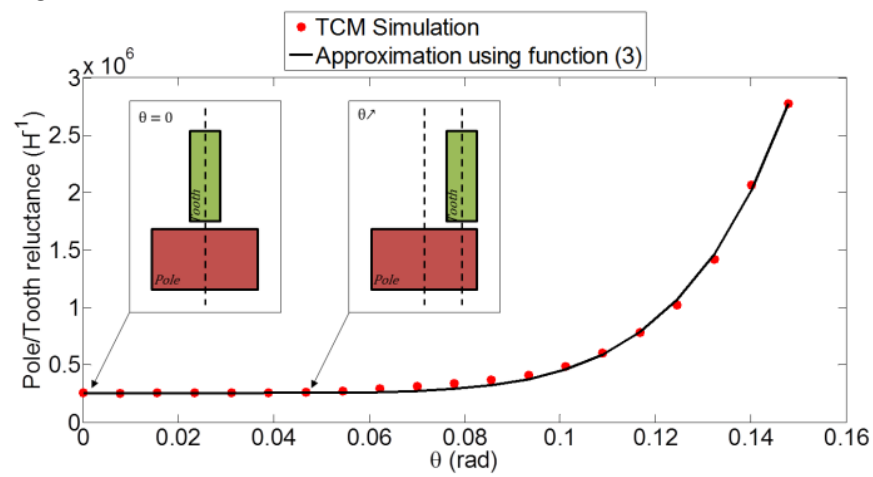

Fig. 8. Evolution of the pole/tooth reluctance as a function of $\theta$.

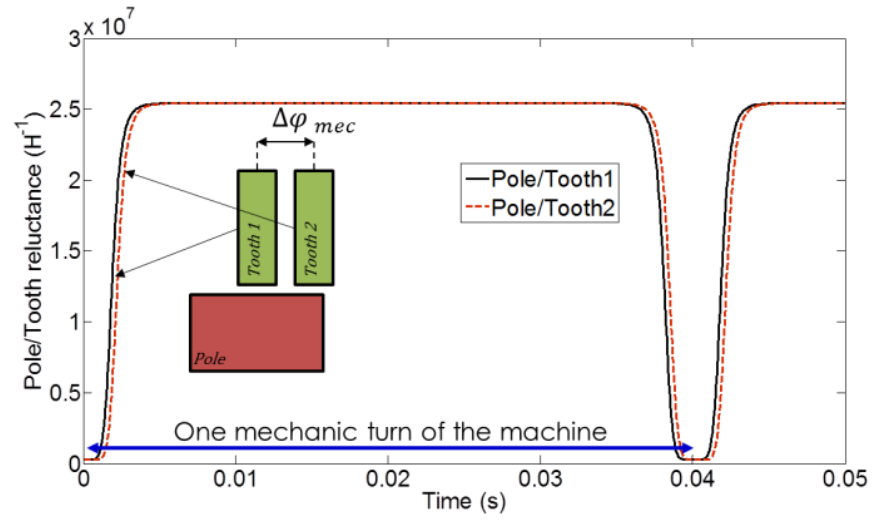

Fig. 9. Periodical evolution of the variable pole/tooth reluctance.

\section{Winding and electrical circuit}

In order to obtain the e.m.f, we use a coupling circuit in view to obtaining the derivative of the totalized flux through each phase [19]. The idea is illustrated in Fig. 10. Firstly, the flux crossing each spire of a phase can be determined by the sum of the fluxes passing the teeth covered by the surface of this spire. The latter, denoted by $\phi_{i=1 . .}^{\text {tooth }}$ where $k$ is the number of the teeth related to the spire, are fluxes crossing the corresponding tooth reluctances in the $\mathrm{RN}$ which can be easily defined once the distribution of the winding is given.

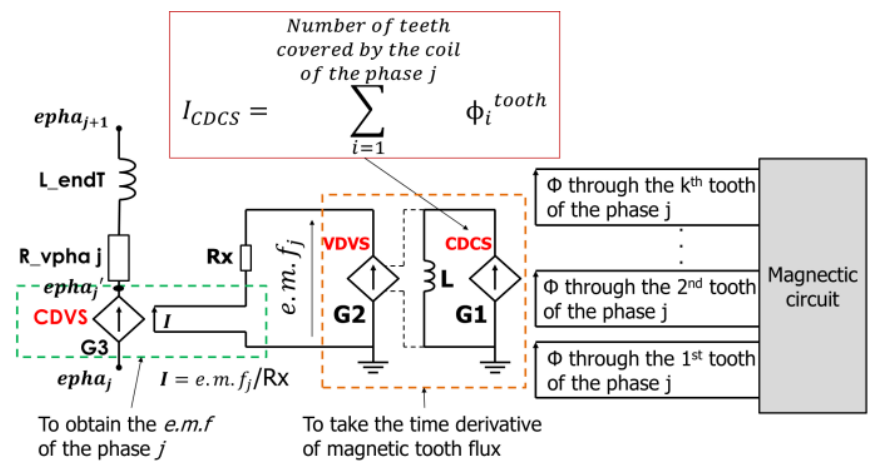

Fig. 10. Coupling circuit used to obtain the phase e.m.f. G1 $=1, \mathrm{G} 2=-\mathrm{N}$, $\mathrm{G} 3=\mathrm{Rx}, e \cdot m \cdot f_{j}=-N d \phi_{\text {total }} / d t$ 


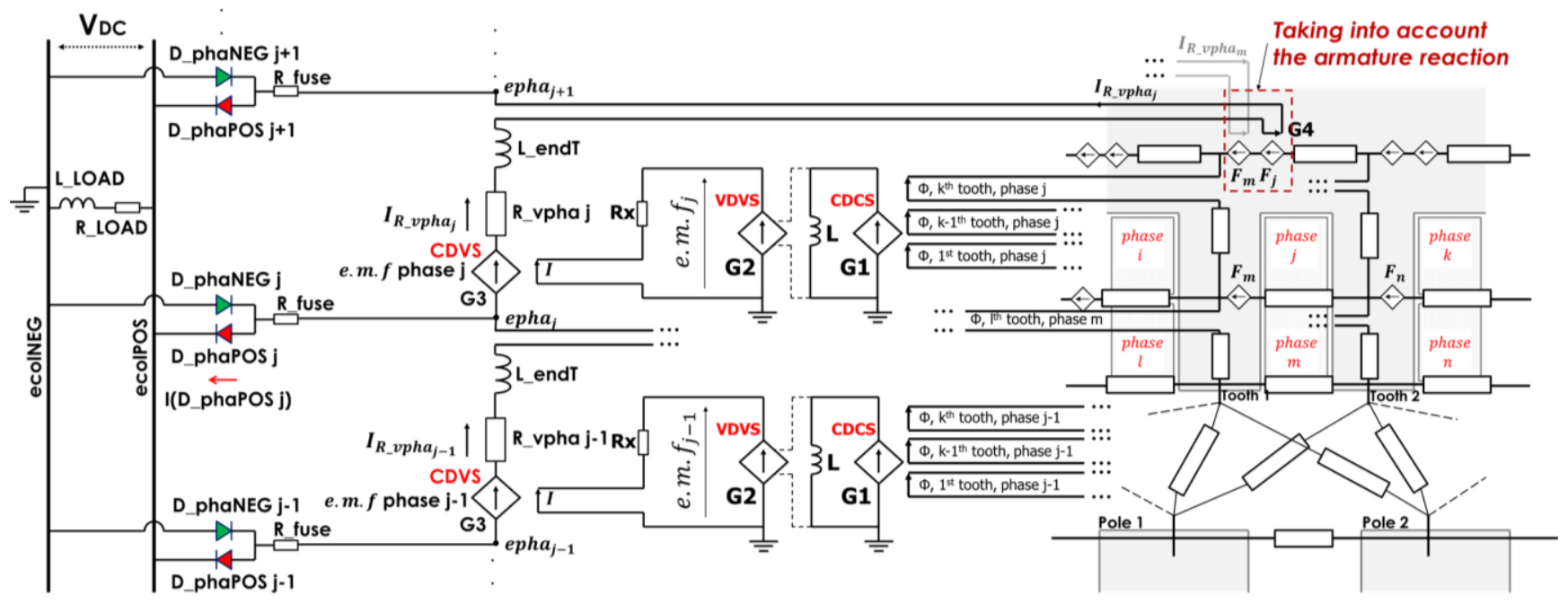

Fig. 11. Coupled circuit model

\section{NO-LOAD SimULATION}

Circuits comprising a Current Dependent Current Source (CDCS) in series with an inductance $\mathrm{L}$ are then used to calculate the time derivative of the total flux $d\left(\sum_{i=\overline{1 . k}} \phi_{i}^{\text {tooth }}\right) / d t$ which is actually the voltage across the inductance L. A Voltage Dependent Voltage Source (VDVS) is then used to capture the time derivative of the total flux and introduce it in the output voltage terminal which is equal to the phase electromotive force $\left(e . m . f_{j}\right)$. The gain $\mathrm{G} 2$ of the VDVS is defined as the number of turns $N$ of the phase coil. The latter is then debited on a resistance of arbitrary value $(\mathrm{Rx})$. The current is proportional to the value of the phase e.m.f. The elements described previously are built once for each phase. Finally, a Current Dependent Voltage Source (CDVS) is used to reconstruct the e.m.f as a voltage across the two terminal nodes of the phase $j$, namely $e p h a_{j}$ and $e p h a_{j}{ }^{\prime}$, of the electrical circuit part. The latter are then connected to the diode bridge, as shown in Fig. 11, where the nodes ecolNEG and ecolPOS are the negative and the positive collector, respectively.

\section{DIODE MODEL}

Fig. 12 shows the plot of the typical characteristic I-V curve of a diode. Its behavior consists of 2 areas:

- When the voltage across the diode $\mathrm{V}_{\mathrm{D}}$ exceeds the threshold voltage $\mathrm{V}_{\text {fwd }}$, the diode is in ON state. Its dynamic resistance $\left(\mathrm{R}_{\mathrm{on}}=\partial \mathrm{V} / \partial \mathrm{I}\right)$ becomes very low, the current increases very quickly with the bias voltage.

- When $\mathrm{V}_{\mathrm{D}}<\mathrm{V}_{\mathrm{fwd}}$, the diode is in blocking state. The current does not vanish but is very low. The diode is considered as a resistance with a very high value.

In our case, the behavior in the breakdown area is not considered.

In the no-load case, the armature current values are practically equal zero. It is not necessary to take their reaction field into consideration. The induced m.m.fs introduced in the armature reluctance circuit can be removed or set to zero. In the following, the simulation results for the magnetic flux obtained with the RN model are compared with a finite element (FE) model using FEMM [20] and ANSYS Maxwell $^{\mathrm{TM}}$ software. We also compare the rectified voltage with measurement data.

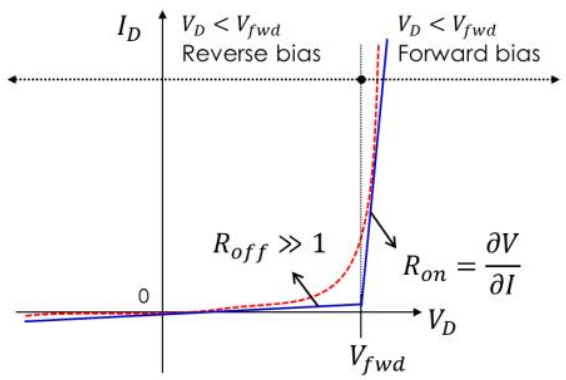

Fig. 12. Diode characteristics

Fig. 13 shows a field distribution obtained with finite elements. The tooth flux is defined as $\phi_{i}^{\text {tooth }}=\int_{s^{\text {tooth }}} \vec{B} \overrightarrow{d s}$ where $S^{\text {tooth }}$ is the surface of the tooth.

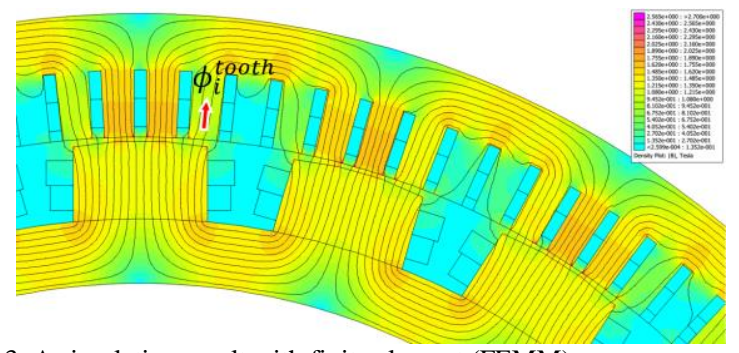

Fig. 13. A simulation result with finite element (FEMM).

Fig. 14 shows a comparison of the time variation of the tooth flux between the RN and the FE models when the rotor turns 
at a constant speed of 1500 (rpm). For this simulation, the computation time of our FE model is 35706 s using a fairly fine mesh whereas it takes 546s with the RN model. Note that in the FE model, the rectifier bridge is not taken into account.

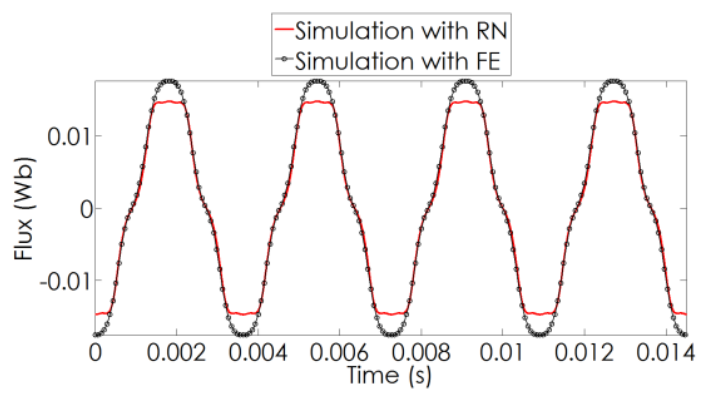

Fig. 14. Comparison with FE of tooth flux, $I_{e x c}=200 \mathrm{~A}$.

Fig. 15 shows the evolution of the rectified voltage between collectors as the excitation current increases, obtained with the experimental measures and the $\mathrm{RN}$ model developed. In the linear region, the $\mathrm{RN}$ model gives a good agreement with measured data. Though, a significant difference is observed in the saturation region. In order to correct the difference, a more detailed reluctance network can be used to better take into account the local saturation effect and the leakage flux.

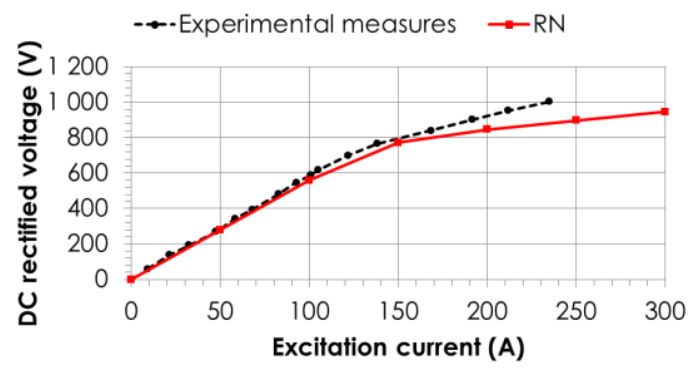

Fig. 15. Comparison of rectified voltage measurements versus various DC excitation currents.

Fig. 16 shows plots of the current in a phase winding of the machine simulated by the $\mathrm{RN}$ and FE models. These simulations are carried out with an excitation current of $220 \mathrm{~A}$.

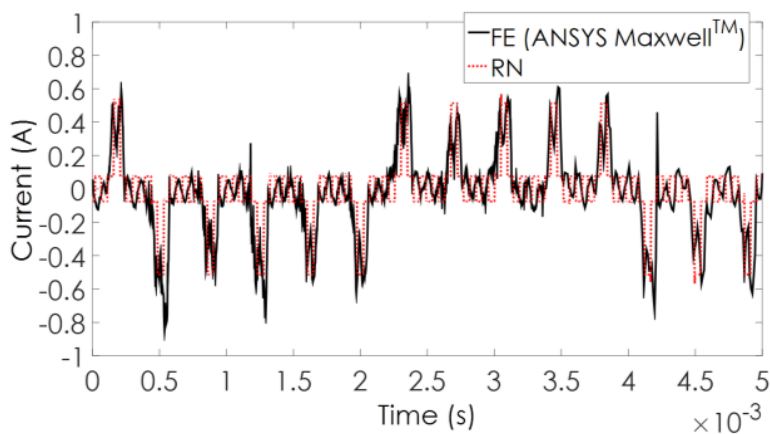

Fig. 16. Simulation of the current in the phase winding with finite element software (ANSYS Maxwell ${ }^{\mathrm{TM}}$ ) and the RN model.

\section{LOAD SIMULATION}

The coupled circuit model presented in Fig. 11 is used to simulate the cases at load. Figs. 17 and 18 show the comparisons between the finite element model and the reluctance network for the phase e.m.f and the phase current obtained with an excitation current of 220A. The RN model agrees well with the FE model. The computation time for this simulation with the $\mathrm{RN}$ is $1.12 \mathrm{~h}$ for $58 \mathrm{~ms}$ of simulation $(0.0193 \mathrm{~h} / \mathrm{ms})$ whereas it takes $77 \mathrm{~h}$ for $5 \mathrm{~ms}$ of simulation with the finite element package or 800 times longer than the RN model. In Figs. 19 and 20, the rectified terminal voltage and the load current are compared with experimental data for rated load tests and short-circuit tests with various excitation currents.

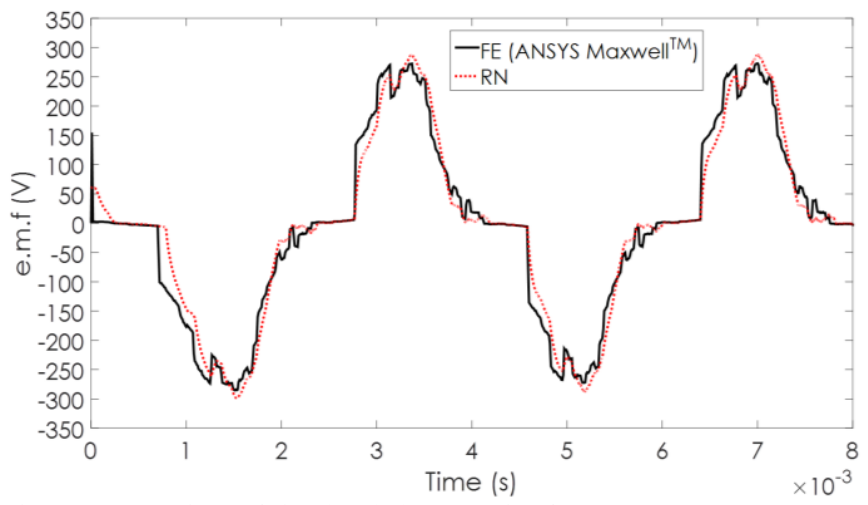

Fig. 17. Comparison of simulated electromotive forces.

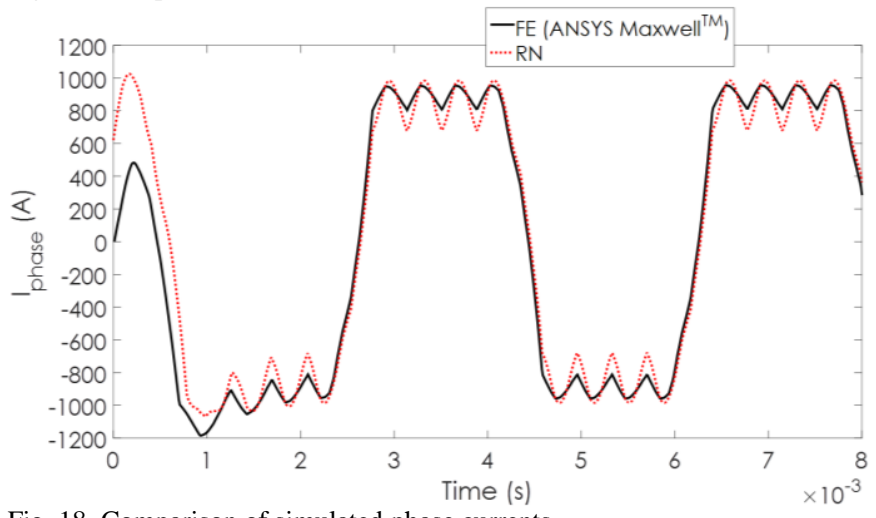

Fig. 18. Comparison of simulated phase currents.

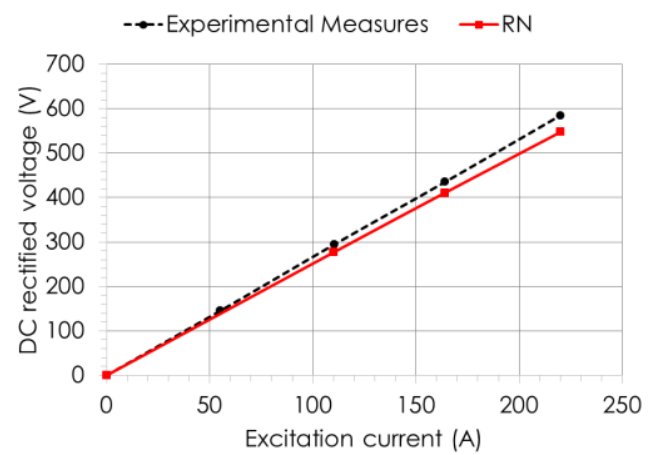

Fig. 19. Comparison of rectified voltage versus excitation current curves in rated load tests.

\section{FAILURE MODE SIMULATION VALIDATION}

In this section, a simulation of a sudden opening of one diode block is carried out. The comparisons with FE simulation are given to validate the RN model. 
In normal mode, the exciter is operated under a field excitation current $I_{\text {exc }}$ of 220A which is supposed constant in all the simulations. The load resistance is $R_{-} L O A D=77.8 \mathrm{~m} \Omega$ (cf. Fig. 11). For our system, the load inductance can be neglected. In steady state, the rectified output voltage $V_{D C}$ is almost constant.

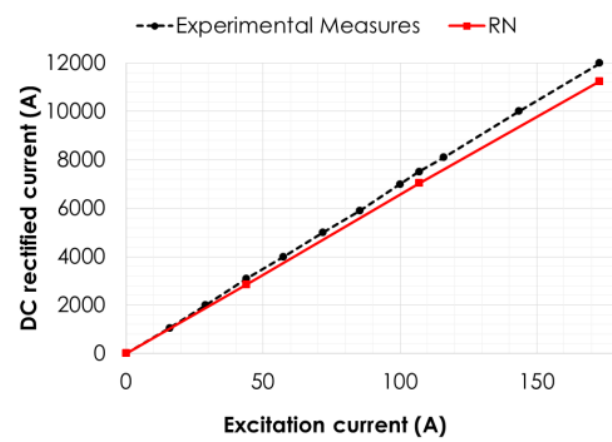

Fig. 20. Comparison of rectified current versus excitation current curves in short-circuit tests.

The opening of a diode block happens when its protection fuse melts due to heat excess. The diode block of the phase 1 (comprising 2 diodes $D \_p h a P O S 1$ and $D \_p h a N E G 1$, $f f$. Fig. 11 with $j=1$ ) is suddenly opened at $0.01 \mathrm{~s}$. The wave form of the output voltage $V_{D C}$ is plotted in Fig. 21. Although voltage ripple is observed, the presence of the fault has little effect on the output voltage which can continue to feed the turboalternator. The simulated wave form of $V_{D C}$ by $\mathrm{RN}$ is in good agreement with FE result as shown in Fig. 22. The difference is of the order of $5 \%$ which is acceptable in this study.

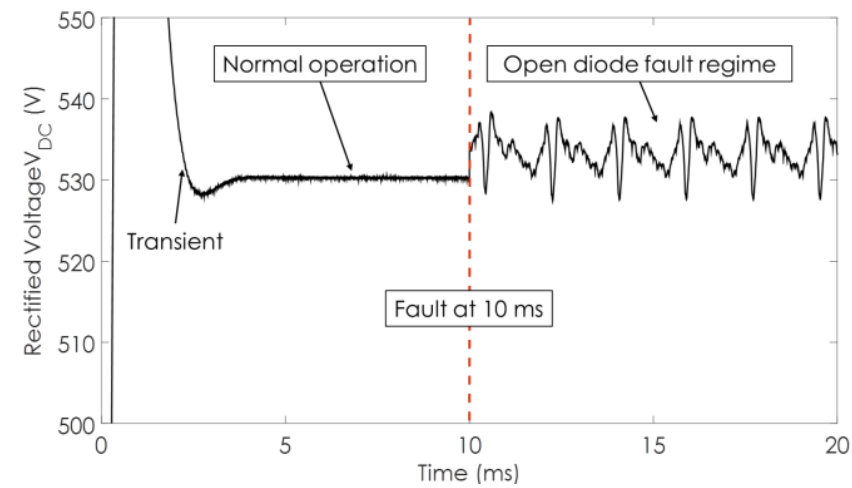

Fig. 21. Simulated rectified voltage by RN model.

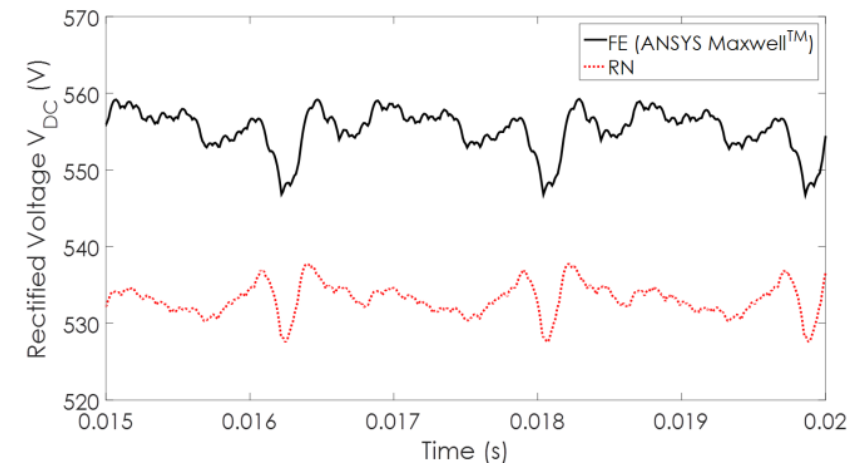

Fig. 22. Comparison of rectified output voltage response in fault regime.
Fig. 23 shows plots of the current in some phase coils of the exciter after the diode block 1 is opened. The distribution of phase currents becomes dissymmetric due to the fact that the conduction instant and the conduction period of diodes are changed. The diode open fault affects strongly phase current wave forms. The RN model gives similar results as finite element software.

The currents through the diodes in the neighbor blocks 2, 3 and 39 ( $c f$. Fig. 11 with $j=1$, note that $j-1$ corresponds to the $39^{\text {th }}$ diode block) are plotted in Fig. 24. The presence of the fault generally increases the current stress on diodes. It will be shown in the next section that this situation is more critical when several diode open faults occurred simultaneously. Fig. 25 gives the comparisons of diode currents between RN and FE models. The result validates the RN model developed.

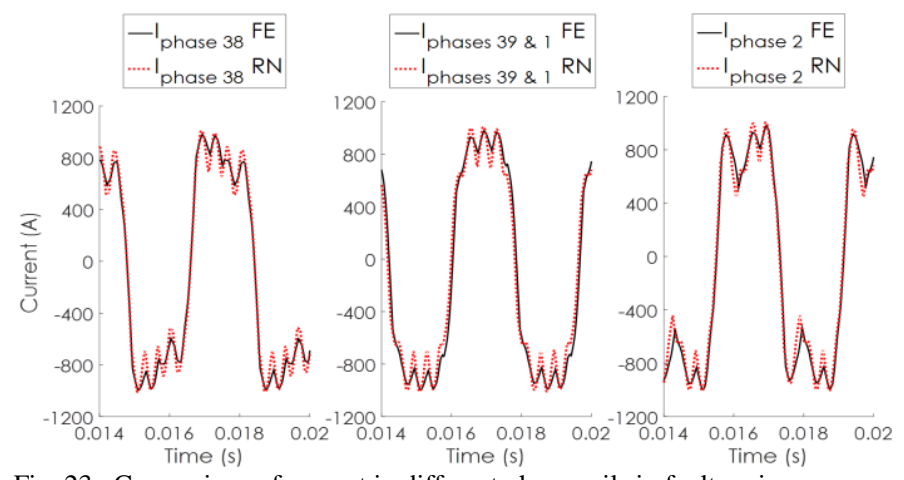

Fig. 23. Comparison of current in different phase coils in fault regime.

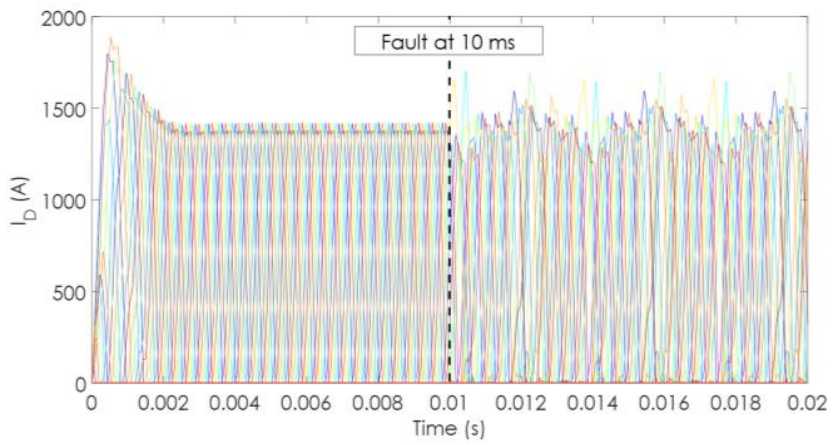

Fig. 24. Simulated current in diodes of different blocks before and after fault given by RN model.

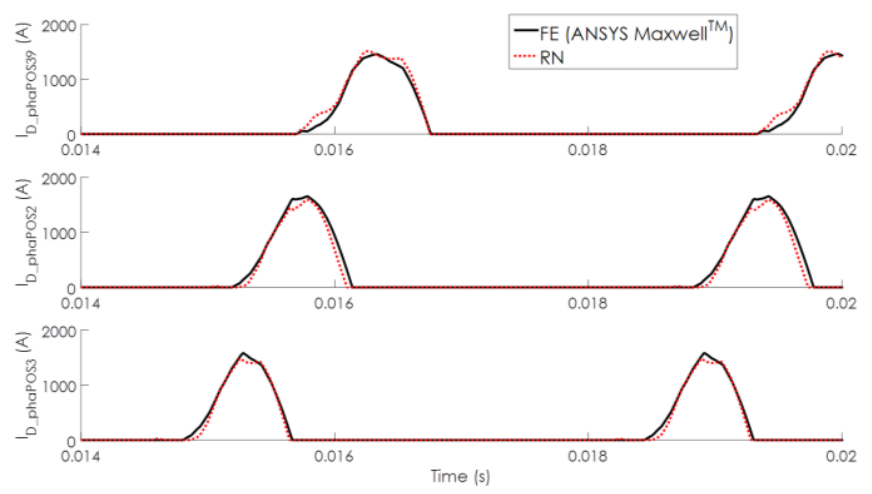

Fig. 25. Comparison of current in diodes of different blocks in fault regime. 


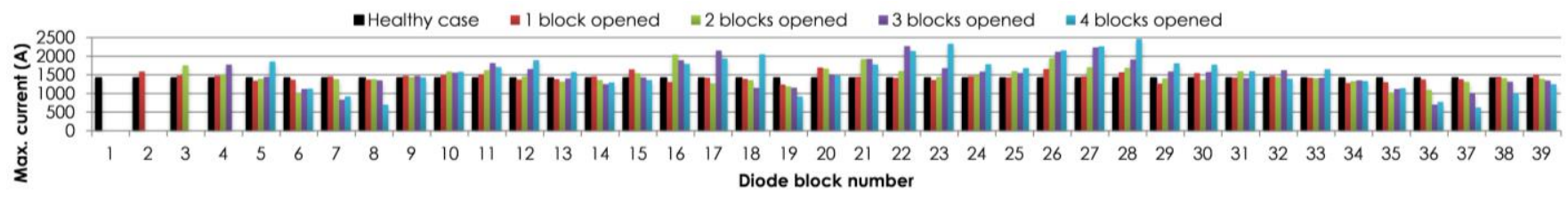

Fig. 26. Maximal value of diode currents in healthy case and faulty cases.

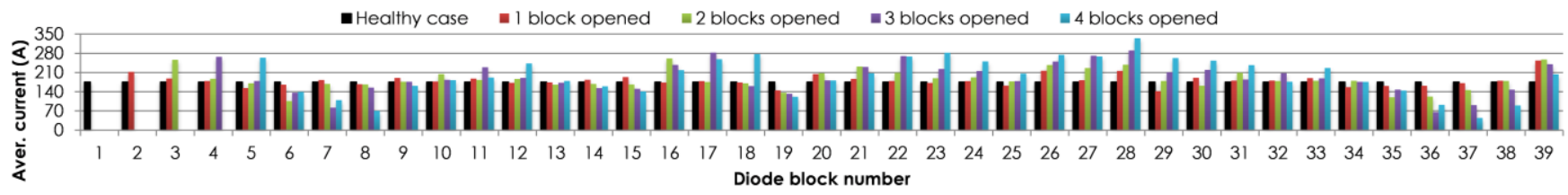

Fig. 27. Average value of diode currents in healthy case and faulty cases.

\section{IMPACT OF DIODE FAILURES}

Using the RN model developed, this section gives the main simulation results of some fault scenarios. Simultaneous diode block open faults due to fuse melting are investigated. The impacts of these faults on the rectified output voltage, phase currents and diode currents are studied.

The healthy case (normal operation) was descripted in the section VII with a constant field current of $220 \mathrm{~A}$ and a load resistance of $77.8 \mathrm{~m} \Omega$. The simulated output voltage is constant and equal to $531 \mathrm{~V}$. The maximal and average values of current in the diodes are 1422A and 175A, respectively. The average current is determined over one electric period by:

$I_{\text {average }}=\frac{1}{T} \int_{t_{0}}^{t_{0}+T} I_{D}(t) d t$

where $T=1 / f_{e}=1 / 275 \mathrm{~s}$. This quantity is related to the thermal stress on diode.

One diode block opened fault was presented in the section VII. In the following, the cases of 2, 3 and 4 blocks opened simultaneously are simulated. These blocks are close each other in the electrical diagram ( $c f$. Fig. 11). For example, in the case of 2 blocks opened, the block comprising D_phaPOS1 and D_phaNEG1 and the block comprising D_phaPOS2 and D_phaNEG2 are opened. In real situation, it may happen since the current in the neighbor diode block is one of the most affected during fault. The protection fuse in these branches may melt due to overcurrent. Only the behavior in steady state of the system is studied. The effect of failure instant is therefore not analyzed.

The output voltage in faulty operations is plotted in Fig. 28. In steady state, the voltage ripple is not higher than $35 \mathrm{~V}$ or $6.6 \%$ of the constant voltage in normal operation. The mean value of the output voltage is almost the same. The exciter could continue its operation. In this case, we estimate the current stress on the others diode blocks. The maximal value and the average value of currents in all blocks are plotted in Fig. 26 and Fig. 27, respectively. It happens that for some diode blocks, the current decreases. However, the faults generally cause more stresses on several other blocks. When the number of opened blocks increases, the maximal forward current and the average forward current in these blocks increase. In these simulations, the diodes in blocks 26, 27 and
28 are the most stressed. If 4 blocks are opened, the maximal current in the block 28 reaches $2466 \mathrm{~A}$ or 1.73 times higher than in normal operation. In this case, the average current in this block is $335 \mathrm{~A}$ which is 1.9 times higher than the normal mode.

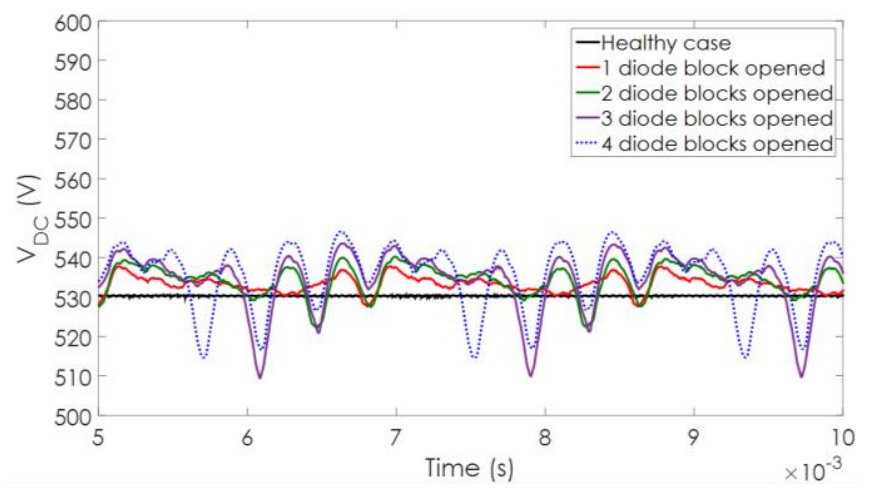

Fig. 28. Simulated rectified output voltage in open diode fault regimes.

If the designed limit of the diode is lower this value, a short-circuit failure may occur. This can happen that fuses will operate and interrupt the current but open other diode blocks creating heavier stresses on the blocks still in service. The risk of successive melting of protection fuses is possible. These results are similar as in [1] which presented a same kind of system. In these cases, the surveillance of fault becomes very necessary in order to prevent serious faults which may lead to an interruption of the operation of the turbo-alternator.

The presence of failures can be directly monitored using the analyses of output voltage and phase current. But due to the fact that the armature of the exciter and the rectifier bridge are located on the rotating part of the system, these quantities are difficult to be accessed. The effect of diode failures on the rectified output voltage can be sensed in the turbo-alternator side. But in the case of "light" fault, the effect may be weak.

It is shown in the previous section that the phase coil currents are much affected in fault regime when 1 diode block is opened (Fig. 23). It is more consequent in the cases that more blocks are opened. Fig. 29 shows plots of the wave form of a phase current in healthy case and in different faulty cases. It is noted that the field current is of $220 \mathrm{~A}$ and the maximal phase coil current is about $1000 \mathrm{~A}$ which is much higher than the latter one. The deformation of the current wave form due 
to faults is therefore significant so that one can expect that its magnetic effect can be capture in the fixed part of the machine.

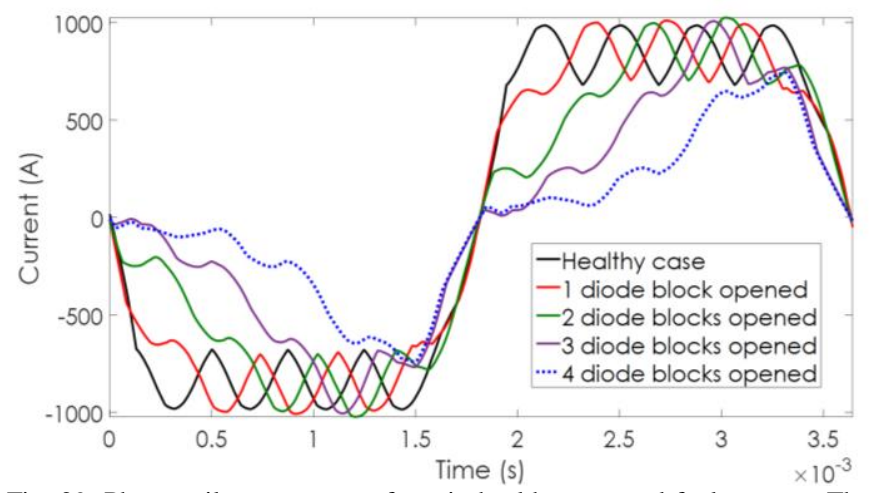

Fig. 29. Phase coil current wave form in healthy case and faulty states. The time interval corresponds to an electrical period $\left(f_{e}=275 \mathrm{~Hz}\right)$.

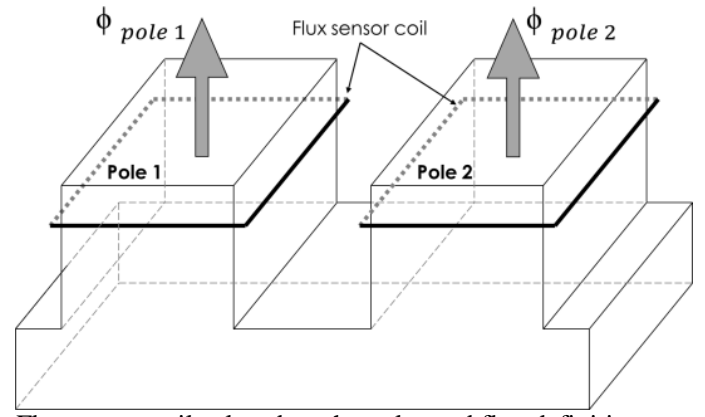

Fig. 30. Flux sensor coils placed on the poles and flux definition associated.

For this kind of system, a flux sensor coil can be disposed to capture the fluxes passing through each magnetic pole of the exciter. Such a system is illustrated in Fig. 30. Stray flux coil can also be placed outside of the machine [21]-[5]. This system is not studied in this work. If the pole flux sensor coils are used, the flux through theses coils can be directly calculated using the RN model. This quantity, namely $\phi_{\text {pole }}$, is actually the flux passing the reluctances RPolel in the schema presented in Fig. 4.

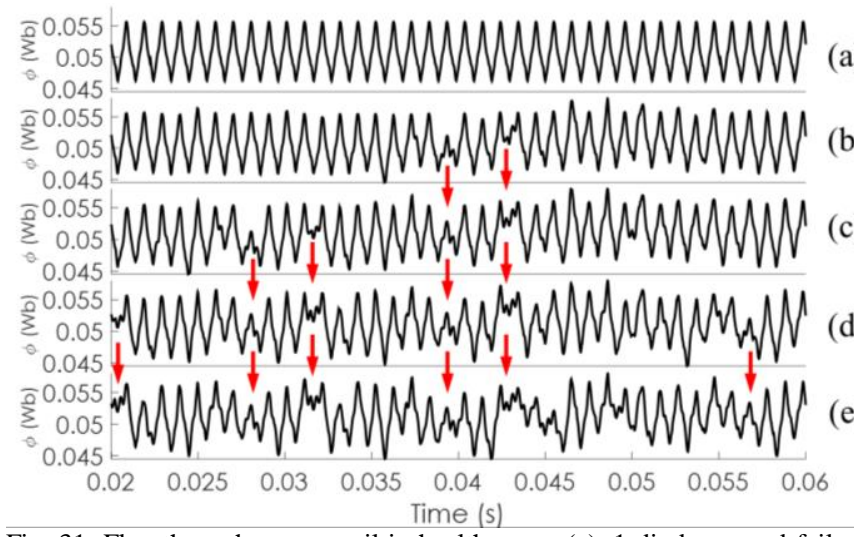

Fig. 31. Flux through sensor coil in healthy case (a), 1 diode opened failure (b), 2 diodes opened failure (c), 3 diodes opened failure (d) and 4 diodes opened failure (e). The time interval of $0.04 \mathrm{~s}$ corresponds to a mechanical period with frequency $f_{m}=25 \mathrm{~Hz}$.

The time evolutions of $\phi_{\text {pole } 1}$ in normal operation and faulty states are plotted in the Fig. 31. The machine takes $0.04 \mathrm{~s}$ to make a complete rotation. This time corresponds to the time interval chosen. The arrows indicate the anomalies in the flux wave form. Some observations can be made. Firstly, the flux sensor "scans" the defective areas where phase coil currents are most affected. Secondly, the anomalies in the flux wave form are inherited for combined failures. For example, the anomalies in the flux wave form in the case of 1 block opened can be also located in the flux wave form in the case of 2 blocks opened due to the fact that the latter case contains the former with an additional block opened. This observation enables the possibility to discriminate faults of different natures. But a detailed analysis is beyond the scope of this paper. We present in the following paragraph a spectrum analysis of the pole flux wave form. This technique was used in [21] and [5] for stray flux coil systems (also called external flux sensors).

The spectra of the pole flux in healthy case and faulty cases are shown in Fig. 32. The chosen fundamental frequency $f_{1}$ of the harmonic $H 1$ corresponds to the mechanical speed of the machine, $1500 \mathrm{rpm}$ or $0.04 \mathrm{~s}$ for one complete rotation, and equal to $25 \mathrm{~Hz}$. The harmonic contents of the FFT of $\phi_{\text {pole }} 1$ and $\phi_{\text {pole } 2}$ are identical and also equal to the other pole fluxes. One needs therefore only one such flux sensor. For these spectra, all the components have been normalized with respect to the main component $(\mathrm{H} 39)$ in healthy case which is set to $100 \%$. In order to remove non-significant harmonic components, only the components higher than $3 \%$ are displayed.

In the healthy case, the frequency components are related to the characteristics of the machine with 39 phases. The harmonic 39 and its multiples (H78, H117 and H156) are obtained. It is noted that we consider a constant field current. Its harmonic components (usually at high frequency) are therefore not taken into account.

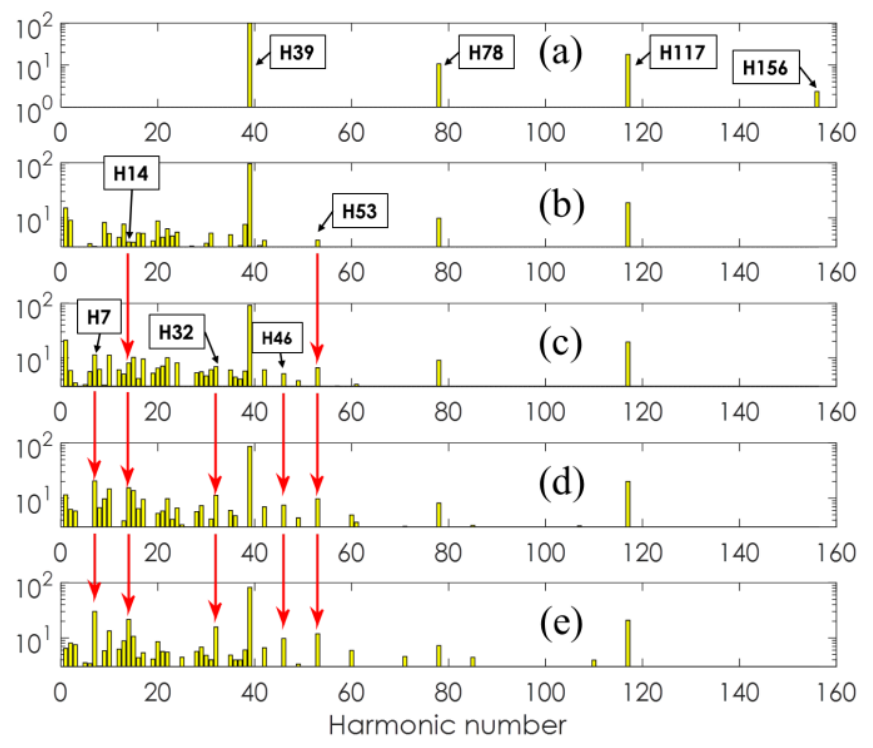

Fig. 32. Spectrum of the sensor flux in healthy case (a), 1 diode opened failure (b), 2 diodes opened failure (c), 3 diodes opened failure (d) and 4 diodes opened failure (e). Let us note that the fundamental frequency (H1) corresponds to the mechanical one $(25 \mathrm{~Hz})$ and the frequency of the H39 is equal to $f_{e} \times 39 / p(975 \mathrm{~Hz})$ where $\mathrm{p}$ is the number of pole pairs. 
In the faulty states, we notice the presence of the low frequency harmonics. In particular, the amplitudes of $\mathrm{H7}$, $\mathrm{H} 14, \mathrm{H} 32, \mathrm{H} 46$ and H53 increase for heavier failures when the number of faulty diode blocks increases. The normalized amplitudes of the harmonic components are given in Table. II.

TABLE II

NORMALIZED VALUE OF SOME HARMONICS OF FLUX (\% with respect to the $\mathrm{H} 39$ in the healthy case)

\begin{tabular}{llllll}
\hline Harmonic & (a) & (b) & (c) & (d) & (e) \\
\hline 7 & 0 & 3 & 11.4 & 20.5 & 30.1 \\
14 & 0 & 3.7 & 8.1 & 15.4 & 21.5 \\
32 & 0 & 2.6 & 6.9 & 11.3 & 15.7 \\
46 & 0 & 2.9 & 5.2 & 7.5 & 9.7 \\
53 & 0 & 4 & 6.6 & 9.7 & 11.9 \\
\hline
\end{tabular}

(a) healthy case, (b) 1 diode opened failure, (c) 2 diodes opened failure, (d) 3 diodes opened failure and (e) 4 diodes opened failure.

\section{CONCLUSION}

The reluctance network coupled with electric circuits and the power electronic components integrating the movement and nonlinearities of materials was developed to analyze a complex machine associated with a rectifier bridge. The armature reaction on the magnetic circuit and the particularity of the winding were taken into consideration. The model was validated by comparisons with finite element simulations and experimental measurements. The approach achieves a good compromise between accuracy and computing time.

The model was used to simulate the exciter system at normal operation and diode opened fault scenarios. Open diode failures are hardly noticed in the turbo-alternator side. For "light" fault when a little number of diode blocks is opened, the rectified voltage is likely not affected. However, these failures increase stresses on other diode blocks. Fuses may melt due to overcurrent to prevent diode short-circuits but open more blocks and increase diode current and heat stress during fault. This situation may lead to serious successive melting failure of protection fuses which can affect the normal operation of the turbo-alternator.

Simulation results show that the presence of open diode failure impacts the armature current waveform. The latter can be observed by a flux sensor coil system placed in the inductor pole of the exciter generator. In order to keep track of possible faults in the rotating diode bridge, harmonic content of the pole flux wave form can be monitored.

In the future, it will be necessary to couple our model with the DC excitation circuit in order to take into account the harmonic components of the field current originating from power electronic converters. A more detailed reluctance network can be developed to take greater account of leakage flux and local saturation phenomena.

\section{REFERENCES}

[1] T. Zouaghi and M. Poloujadoff, "Modeling of polyphase brushless exciter behavior for failing diode operation," IEEE Transactions on Energy Conversion, vol. 13, no. 3, pp. 214-220, Sep 1998.

[2] T. Zouaghi, P. Barret, D. Vielpeau, M. Poloujadoff, "Modelling of rectified polyphase salient-pole synchronous machines: Influence of end-winding leakages on short-circuit operation diode current," Euro. Trans. Electr. Power, vol. 7, no. 4, 1997.

[3] T. W. Nehl, F. A. Fouad and N. A. Demerdash, "Determination of Saturated Values of Rotating Machinery Incremental and Apparent Inductances by an Energy Perturbation Method," IEEE Transactions on Power Apparatus and Systems, vol. PAS-101, no. 12, pp. 4441-4451, Dec. 1982.

[4] N. Sivakumar, B. Bhangu, S. K. Panda and A. K. Gupta, "Dynamic model of Brushless Synchronous Generator with turn-to-turn short circuit fault for condition monitoring," ECCE Asia Downunder (ECCE Asia), 2013 IEEE, Melbourne, VIC, 2013, pp. 258-263.

[5] M. Salah, K. Bacha, A. Chaari and M. El Hachemi Benbouzid, "Brushless Three-Phase Synchronous Generator Under Rotating Diode Failure Conditions," IEEE Transactions on Energy Conversion, vol. 29, no. 3, pp. 594-601, Sept. 2014.

[6] R. Wamkeue, I. Kamwa and M. Chacha, "Line-to-line short-circuitbased finite-element performance and parameter predictions of large hydrogenerators," IEEE Transactions on Energy Conversion, vol. 18, no. 3, pp. 370-378, Sept. 2003.

[7] S. E. Dallas, A. N. Safacas and J. C. Kappatou, "Interturn Stator Faults Analysis of a 200-MVA Hydrogenerator During Transient Operation Using FEM," IEEE Transactions on Energy Conversion, vol. 26, no. 4, pp. 1151-1160, Dec. 2011.

[8] T. Raminosoa, J.A. Farooq, A. Djerdir, A. Miraoui, "Reluctance network modelling of surface permanent magnet motor considering iron nonlinearities," Energy Conversion and Management, vol. 50, no. 5, pp. 1356-1361, May 2009.

[9] A. Mahyob, P. Reghem and G. Barakat, "Permeance Network Modeling of the Stator Winding Faults in Electrical Machines," IEEE Transactions on Magnetics, vol. 45, no. 3, pp. 1820-1823, March 2009.

[10] H. K. Bui, N. Bracikowski, M. Hecquet, K. L. Zappellini, J. P. Ducreux, "Simulation of large power brushless synchronous generator (BLSG) with rotating rectifier by reluctance network for fault analysis" in Proc. 2016 XXII Intl. Conf. on Elec. Mach. (ICEM), Ecublens, Switzerland, pp. $2887-2893$.

[11] V. Ostovic, "A novel method for evaluation of transient states in saturated electric machines," IEEE Trans. on Industry Applications, vol. 25, no. 1, pp. 96-100, Jan.-Feb. 1989.

[12] N. Bracikowski, M. Hecquet, P. Brochet, S.V. Shirinskii, "Multiphysics Modeling of a Permanent Magnet Synchronous Machine by Using Lumped Models," IEEE Transactions on Industrial Electronics, vol.59, no.6, pp.2426-2437, June 2012.

[13] M. Hecquet, P. Brochet, "Modeling of a claw-pole alternator using permeance network coupled with electric circuits," IEEE Transactions on Magnetics, vol.31, no.3, pp.2131-2134, May 1995.

[14] H. Roisse, M. Hecquet, and P. Brochet, "Simulations of synchronous machines using a electric-magnetic coupled network model," IEEE Trans. Magn., vol. 34, no. 5, pp. 3656-3659, 1998.

[15] F. Hecht, A. Marrocco, F. Piriou, and A. Razek, "Modélisation de systèmes électrotechniques par couplage des équations électriques et magnétiques," Rev. Phys. Appl., vol. 25, no. 7, pp. 649-659, 1990.

[16] E. Ilhan, J. Paulides, L. Encica, and E. Lomonova, "Tooth Contour Method Implementation for the Flux-Switching PM Machines," XIX Int. Conf. Electr. Mach., pp. 1-6, 2010.

[17] E. Ilhan, E. Motoasca, J. Paulides, and E. Lomonova, "Conformal mapping: Schwarz-Christoffel Method for Flux-Switching PM Machines," Math. Sci., vol. 6, no. 1, p. 37, 2012.

[18] L. Dang, N. Bernard, N. Bracikowski and G. Berthiau, "Analytical model and reluctance network for high-speed PMSM design optimization application to electric vehicles," 2016 XXII International Conference on Electrical Machines (ICEM), Lausanne, 2016, pp. $1359-1365$.

[19] K. Nakamura, O. Ichinokura, M. Maeda, S. Akatsuka, K. Takasugi, H. Sato, "Analysis of orthogonal-core type linear variable inductor and application to VAR compensator," IEEE Transactions on Magnetics, vol.36, no.5, pp.3565-3567, Sep 2000.

[20] http://www.femm.info/

[21] H. Henao, C. Demian and G. A. Capolino, "A frequency-domain detection of stator winding faults in induction machines using an external flux sensor," IEEE Transactions on Industry Applications, vol. 39, no. 5, pp. 1272-1279, Sept.-Oct. 2003. 